\title{
Effect of high body mass index on knee muscle strength and function after anterior cruciate ligament reconstruction using hamstring tendon autografts
}

Wei-Hsiu Hsu ${ }^{1,2,3^{*}}$ (D) Chun-Hao Fan ${ }^{1}$, Pei-An Yu ${ }^{1,2}$, Chi-Lung Chen ${ }^{1,2,3}$, Liang-Tseng Kuo 1,2,3 and Robert Wen-Wei Hsu ${ }^{1,2}$

\begin{abstract}
Background: Increased body mass index (BMI) has been associated with poorer function in patients who have undergone anterior cruciate ligament $(\mathrm{ACL})$ reconstruction. However, the effect of high BMI on muscle strength in these patients remained unclear. The current study aimed to compare knee muscle strength and Knee injury and Osteoarthritis Outcome Score (KOOS) in ACL-reconstructed patients with a variety of different BMIs.

Methods: From November 2013 to March 2016, we prospectively enrolled 30 patients who underwent ACL reconstruction (18-60 years of age). Anthropometric parameters, body compositions, isokinetic muscle strength and KOOS were assessed preoperatively, and at post-operative 16th week and 28th week. The patients were stratified into two groups by BMl, i.e. normal BMl $\left(18.5-24.9 \mathrm{~kg} / \mathrm{m}^{2}\right)$ and high BMI $\left(\geq 25.0 \mathrm{~kg} / \mathrm{m}^{2}\right)$.

Results: Twelve patients in the normal BMI group completed the follow-up, while sixteen patients did so in the high BMI group. In comparison of muscle strength between baseline and 28th week follow-up, the normal BMI group had significant increases in overall knee muscle strength, while the high BMI group only had increases in extensors of uninjured knee and flexors of the injured knee. However, there were significant increases in all KOOS subscales for the high BMI group. The high BMI patients reported increased KOOS, which may reflect the contribution of ligament stability in the presence of inadequate muscle strength.

Conclusions: The normal BMI patients had improvement in all knee muscle strength following ACL reconstruction, while high BMI patients only had increases in certain knee muscles. High BMI patients had a decreased quadriceps muscle symmetry index, as compared to their normal BMI counterparts. Increases in quadriceps muscle strength of the uninjured knee and $\mathrm{ACL}$ reconstruction were associated with improvements in KOOS in high BMI patients.
\end{abstract}

Keywords: Body composition, BMI, Leg symmetry index

\section{Background}

Anterior cruciate ligament (ACL) reconstruction surgery aims to re-establish the stability in the knee joint and allow patients to return to their previous activities after a period of muscle training [1]. Many factors have been suggested as contributing to self-reported function results for

\footnotetext{
* Correspondence: 7572@cgmh.org.tw

${ }^{1}$ Sports Medicine Center, Chang Gung Memorial Hospital at Chia Yi, Chia Yi, Taiwan

${ }^{2}$ Department of Orthopaedic Surgery, Chang Gung Memorial Hospital at Chia Yi, No 6 West section, Chia Pu Road, Puzih, Chia Yi Hsien 613, Taiwan
} Full list of author information is available at the end of the article
ACL reconstruction, including quadriceps index, pain intensity, and flexion motion deficit [2]. The effect of body mass index (BMI) on long-term outcome for ACL reconstruction patients remained unclear [3]. Increased BMI has been associated with poorer functional outcomes following ACL reconstruction [4, 5]. Meanwhile, ACL reconstruction has also been suggested as an effective treatment irrespective of preoperative BMI [6].

Whether the quadriceps recovers well is a major concern for function following ACL injury and reconstruction, as well as a determining factor in the development

(c) The Author(s). 2018 Open Access This article is distributed under the terms of the Creative Commons Attribution 4.0 International License (http://creativecommons.org/licenses/by/4.0/), which permits unrestricted use, distribution, and reproduction in any medium, provided you give appropriate credit to the original author(s) and the source, provide a link to the Creative Commons license, and indicate if changes were made. The Creative Commons Public Domain Dedication waiver (http://creativecommons.org/publicdomain/zero/1.0/) applies to the data made available in this article, unless otherwise stated. 
of knee osteoarthritis [7-9]. The quadriceps of the injured knee weakens profoundly after anterior cruciate ligament injury and subsequent reconstruction [7, 9-11]. This weakness of the quadriceps muscle has been attributed to arthrogenic inhibition, incomplete voluntary activation of the muscle, and altered quadriceps corticomotor excitability [12-14]. It is generally accepted that the aim of postoperative care should be focused on the recovery of muscle strength after ACL reconstruction [15-17]. In fact, quadriceps strength did affect self-reported knee function [2, 18, 19].

Although it has been found that increased BMI is associated with slower muscle recovery as well as lower quadriceps muscle force in patients following total knee arthroplasty [20], whether this slow recovery occurs in ACL patients was previously unclear. Therefore, the purpose of this study was to compare body compositions, knee muscle strength, and Knee Injury and Osteoarthritis Outcome Score (KOOS) after ACL reconstruction in patients with different BMIs.

\section{Methods}

Between November 2013 and March 2016, we prospectively enrolled 30 patients who underwent anterior cruciate ligament reconstructions (aged 18-60 years) using hamstring tendon autografts. The individuals were excluded if they (1) had a history of surgery to either knee, (2) had a previous partial ACL tear, (3) had other ligamentous damage concurrent with ACL injury, (4) had any complications or additional surgery during follow-up. Since return to activity were usually advised 6 months after ACL reconstruction, end-point assessments were performed at 28 weeks after ACL reconstruction [21, 22]. To understand the temporal changes following ACL reconstruction, 16 weeks were further selected. The anthropometric parameters, body compositions, muscle strength and KOOS were assessed preoperatively, and then 16 weeks and 28 weeks post operatively. All participants were Taiwanese from the southern part of the country. The present study was approved by the institutional review board of Chang Gung Foundation (IRB102-0977B), and all study participants provided informed consent to be involved in the study.

\section{Muscle strength}

The muscle strength of the lower extremity including knee flexor/extensor was tested via the HUMAC NORM system (CSMi, U.S.A.), with the mode of concentric/concentric contraction at the angular velocity of 60 degrees/ $\mathrm{s}[11,15,23]$. The knee flexor/extensor was tested in a seated position. Isokinetic tests were performed 5 times for each examination, and each trial was separated by a rest period of $3 \mathrm{~min}$. In the present study, muscle strength was then normalized for body weight [11]. Leg symmetry index was calculated via the equation ((Injured side maximum force/uninjured side maximum force) $\times 100 \%)$, and compared $[12,24]$.

\section{Body composition}

Body composition was assessed using an eight-polar tactile-electrode impedance meter (InBody 720; Biospace, Seoul, Korea), which simultaneously recorded body weight, total body fat mass, and lean body mass [25]. BMI $\left(\mathrm{kg} / \mathrm{m}^{2}\right)$ was calculated as follows: $\mathrm{BMI}=$ weight $/$ height $^{2}$. The participants were divided into two groups stratified by BMI. The classification of high BMI was based on BMI cut-points established by the World Health Organization. Two levels were determined: the normal BMI group $\left(18.5-24.9 \mathrm{~kg} / \mathrm{m}^{2}\right)$ and the high BMI goup $\left(\geq 25.0 \mathrm{~kg} / \mathrm{m}^{2}\right)[6,26]$.

\section{Questionnaire}

The Knee Injury and Osteoarthritis Outcome Score is a 42-item self-administered knee-specific questionnaire assessing pain (9 items), symptoms (7 items), activities of daily living (ADL, 17 items), function, sports and recreational activities (Sports/Rec, 5 items) and knee-related quality of life (QOL, 4 items) in five separate subscales. All items are scored 0 to 4 ; for each subscale the scores are converted to a 0 to 100 scale $(0$ representing extreme knee problems and 100 representing no knee problems) [27].

The Marx activity rating scales is a patient-reported instrument which is determined by measuring some components of physical function that are common to the most sporting activities [28].

\section{Exercise protocol}

It was suggested the importance of improving lower limb muscle strength, starting at an date (2-6 weeks) early after surgery [29-31]. The participants were prescribed home based rehabilitation protocol that started at 4 weeks after surgery. Telephone to track the implementation of this rehabilitation protocol was performed weekly. The rehabilitation program was $1 \mathrm{~h}$ stretching and resistance training, with the use of a resistive band instead of weights, 3-5 times per week for 24 weeks. The stretching consisted of eight movements (lower back stretch, upper back stretch, hip stretch, quadriceps stretch, abdomen stretch, lower leg stretch, arm stretch and groin stretch), each held for 20-30 s. The resistance exercises were completed by side bending, biceps curl, leg extension, seated dip, shoulder press, hip abductor/ adductor, chest press and leg press. To minimize fatigue, the exercises were alternated between the upper and lower body. Each movement was 4 sets of 15 repetitions. There was a rest interval between sets of $60 \mathrm{~s}$, but no pauses between repetitions. 
Table 1 Subject characteristics

\begin{tabular}{|c|c|c|c|}
\hline & \multirow{2}{*}{$\begin{array}{l}\text { Normal BMI } \\
\text { group }(N=12) \\
\text { Mean } \pm S D\end{array}$} & $\begin{array}{l}\text { High BMl group } \\
(N=16)\end{array}$ & \multirow[t]{2}{*}{$p$ value } \\
\hline & & Mean $\pm S D$ & \\
\hline Age (years) & $41 \pm 13$ & $35 \pm 13$ & 0.270 \\
\hline Height (cm) & $164 \pm 9$ & $171 \pm 8$ & 0.092 \\
\hline $\begin{array}{l}\text { Time from injury to } \\
\text { baseline test (mon) }\end{array}$ & $17 \pm 28$ & $5 \pm 5$ & 0.319 \\
\hline $\begin{array}{l}\text { Marx activity rating } \\
\text { scales (score) }\end{array}$ & $7 \pm 6$ & $7 \pm 6$ & 0.700 \\
\hline Male:Female ratio & $7: 5$ & 13: 3 & 0.085 \\
\hline $\begin{array}{l}\text { Meniscal damage } \\
\text { Yes:No ratio }\end{array}$ & $7: 5$ & 11: 5 & 0.143 \\
\hline $\begin{array}{l}\text { Cause of injury } \\
\text { Sport:Other ratio }\end{array}$ & $8: 4$ & 10: 6 & 0.558 \\
\hline
\end{tabular}

\section{Statistical analysis}

All data analyses were performed using the Statistical Package for the Social Sciences for Windows (v 20.0; SPSS Inc., Chicago, IL, USA). All continuous data is presented as the mean \pm standard deviation (SD). A two-way analysis of variance (ANOVA; group $\times$ time) with repeated measures was used to determine the effects of BMI group and time on the dependent measures. The level of significance was set at $p \leq 0.05$. A power of $95 \%$ and relevant effect size of 0.31 was calculated.

\section{Results}

Twenty-eight patients completed the follow-up test at 28 weeks, including twelve patients in the normal BMI group $\left(\mathrm{BMI}=18.5-24.9 \mathrm{~kg} / \mathrm{m}^{2}\right)$ and sixteen in the high BMI group (BMI $\geq 25.0 \mathrm{~kg} / \mathrm{m}^{2}$ ) (i.e., at least $75 \%$ of the training sessions). The reasons for loss of follow-up in the present study were personal factors, such as moving house. The demographic data showed no differences between both groups other than body weight (Table 1). However, it was found that high BMI patients underwent surgical interventions in a shorter interval after injury, and suffered an increased rate of concomitant meniscal injury. Causes of initial injury include: sports (basketball, volleyball and badminton), falling or car accident.

In body composition analysis, we observed a temporary increase in body fat in both the normal and high BMI groups at 16 weeks following ACL reconstruction, then returning to previous level at 28 weeks. Interestingly, an increase in lean body mass was shown in the high BMI group at 28 weeks after ACL reconstruction, which resulted in a corresponding increase in body weight. On the other hand, no difference was shown in the normal BMI group in either lean body weight or fat mass (Table 2).

In isokinetic muscle strength assessment, knee muscle strength increased for both knee flexor and extensor in the injured knee for the normal BMI group at the 28-

Table 2 Body composition

\begin{tabular}{|c|c|c|c|c|c|c|c|}
\hline & & Baseline & 16 weeks & 28 weeks & ${ }^{\ddagger} p$ value & ${ }^{\S} p$ value & ${ }^{\delta} p$ value \\
\hline & & Mean $\pm S D$ & Mean \pm SD & Mean $\pm S D$ & & & \\
\hline \multirow[t]{3}{*}{ Weight (kg) } & Normal BMI group & $61 \pm 9+$ & $62 \pm 10^{\neq \dagger}$ & $62 \pm 10^{\dagger}$ & 0.028 & 0.175 & 0.263 \\
\hline & High BMI group & $85 \pm 12$ & $86 \pm 12$ & $86 \pm 12$ & 0.134 & 0.214 & 0.938 \\
\hline & ${ }^{\dagger} p$ value & $<0.001$ & $<0.001$ & $<0.001$ & & & \\
\hline \multirow[t]{3}{*}{ BMI $\left(\mathrm{kg} / \mathrm{m}^{2}\right)$} & Normal BMI group & $23 \pm 2^{\dagger}$ & $23 \pm 2^{+}$ & $23 \pm 2^{\dagger}$ & 0.641 & 0.528 & 0.326 \\
\hline & High BMI group & $29 \pm 3$ & $29 \pm 4$ & $29 \pm 3$ & 0.277 & 0.414 & 0.775 \\
\hline & ${ }^{\dagger} p$ value & $<0.001$ & $<0.001$ & $<0.001$ & & & \\
\hline \multirow[t]{3}{*}{ LBM (kg) } & Normal BMI group & $45 \pm 8^{+}$ & $45 \pm 8^{\dagger}$ & $45 \pm 8^{\dagger}$ & 0.672 & 0.553 & 0.326 \\
\hline & High BMI group & $60 \pm 9$ & $60 \pm 10$ & $61 \pm 10^{\S \delta}$ & 0.682 & 0.017 & 0.049 \\
\hline & ${ }^{\dagger} p$ value & 0.002 & 0.003 & 0.001 & & & \\
\hline \multirow[t]{3}{*}{ Body fat (kg) } & Normal BMI group & $16 \pm 3^{\dagger}$ & $17 \pm 3^{\neq \dagger}$ & $16 \pm 4^{\dagger}$ & 0.012 & 0.735 & 0.141 \\
\hline & High BMI group & $25 \pm 8$ & $26 \pm 8^{\neq}$ & $25 \pm 8 \delta$ & 0.034 & 0.865 & 0.036 \\
\hline & ${ }^{\dagger} p$ value & 0.004 & 0.004 & 0.005 & & & \\
\hline \multirow[t]{3}{*}{ LBM/ body fat ratio (\%) } & Normal BMI group & $291 \pm 55$ & $267 \pm 60^{\ddagger}$ & $291 \pm 71 \delta$ & 0.002 & 0.994 & 0.042 \\
\hline & High BMl group & $260 \pm 84$ & $252 \pm 86^{\ddagger}$ & $263 \pm 86$ & 0.042 & 0.678 & 0.073 \\
\hline & ${ }^{\dagger} p$ value & 0.391 & 0.624 & 0.391 & & & \\
\hline
\end{tabular}

LBM Lean body mass

${ }^{\dagger} p \leq 0.05$ between normal and high BMl group

${ }^{\S} p \leq .05$ between baseline and 28 weeks

${ }^{\ddagger} p \leq .05$ between baseline and 16 weeks

${ }^{\delta} p \leq .05$ between 16 weeks and 28 weeks 
Table 3 Modulus knee muscle strength (N-m)

\begin{tabular}{|c|c|c|c|c|c|c|c|c|}
\hline & & & Baseline & 16 weeks & 28 weeks & ${ }^{\ddagger} p$ value & ${ }^{\S} p$ value & $\delta_{p} p$ value \\
\hline & & & Mean \pm SD & Mean $\pm S D$ & Mean $\pm S D$ & & & \\
\hline Injury side & Extensor & Normal BMI group & $42 \pm 31$ & $65 \pm 33^{\ddagger}$ & $75 \pm 40^{\S \delta}$ & 0.028 & 0.011 & 0.042 \\
\hline & & High BMI group & $64 \pm 35$ & $66 \pm 36$ & $76 \pm 36$ & 0.777 & 0.213 & 0.181 \\
\hline & & $t p$ value & 0.152 & 0.937 & 0.938 & & & \\
\hline & Flexor & Normal BMl group & $35 \pm 18^{\dagger}$ & $51 \pm 12$ & $66 \pm 25 \S$ & 0.066 & 0.011 & 0.072 \\
\hline & & High BMl group & $58 \pm 26$ & $61 \pm 23$ & $73 \pm 25$ & 0.671 & 0.055 & 0.065 \\
\hline & & ${ }^{\dagger} p$ value & .034 & 0.287 & 0.520 & & & \\
\hline Uninjured side & Extensor & Normal BMl group & $76 \pm 40$ & $99 \pm 30$ & $96 \pm 36^{\S}$ & 0.097 & 0.004 & 0.754 \\
\hline & & High BMl group & $101 \pm 39$ & $120 \pm 46$ & $131 \pm 42^{\S}$ & 0.068 & 0.003 & 0.296 \\
\hline & & ${ }^{\dagger} p$ value & 0.152 & 0.271 & 0.058 & & & \\
\hline & Flexor & Normal BMI group & $48 \pm 16^{\dagger}$ & $66 \pm 14^{\ddagger}$ & $67 \pm 20^{\S}$ & 0.015 & 0.002 & 0.921 \\
\hline & & High BMl group & $75 \pm 26$ & $85 \pm 29$ & $89 \pm 32$ & 0.088 & 0.094 & 0.648 \\
\hline & & ${ }^{\dagger} p$ value & 0.016 & 0.109 & 0.054 & & & \\
\hline
\end{tabular}

${ }^{\dagger} p \leq 0.05$ between normal and high BMI group

${ }^{\S} p \leq .05$ between baseline and 28 weeks

${ }^{\ddagger} p \leq .05$ between baseline and 16 weeks

${ }^{\delta} p \leq .05$ between 16 weeks and 28 weeks

week follow-up. At the same time, an increase was shown only in the knee flexor muscle in the high BMI group. For the uninjured knee, the normal BMI group had simultaneously increased strength in both the knee extensor and flexor. On the contrary, an increase was demonstrated in extensor muscle strength for the uninjured knee in the high BMI group, as well as an increase in flexor muscle strength of the injured knee (Tables 3 and 4). When the symmetry index was calculated and compared, the normal BMI group had a significant increase in the symmetry index as compared to the high BMI group at the 28-week follow-up (Fig. 1).
In the functional assessment via KOOS, there were no differences in any category between the normal and high BMI groups, except in QOL score. The high BMI group had a decreased QOL score as compared to those in the normal BMI group at baseline $(p \leq 0.05)$. These differences in QOL became insignificant at 28 weeks after ACL reconstruction (Table 5). For the high BMI group, the KOOS increased from baseline to 28 weeks after ACL reconstruction in all categories. The symptom score increased from $62 \pm 17$ to $74 \pm 15(p \leq 0.05)$. Similar increases were found in pain, ADL and QOL score (Table 5). Meanwhile, the sport/recreational activity

Table 4 Relative knee muscle strength ( $\mathrm{N}-\mathrm{m} / \mathrm{kg})$

\begin{tabular}{|c|c|c|c|c|c|c|c|c|}
\hline & & & \multirow{2}{*}{$\begin{array}{l}\text { Baseline } \\
\text { Mean } \pm S D\end{array}$} & \multirow{2}{*}{$\begin{array}{l}16 \text { weeks } \\
\text { Mean } \pm S D\end{array}$} & \multirow{2}{*}{$\begin{array}{l}28 \text { weeks } \\
\text { Mean } \pm S D\end{array}$} & \multirow{2}{*}{$\begin{array}{l}{ }^{+} p \\
\text { value }\end{array}$} & \multirow{2}{*}{$\begin{array}{l}{ }^{\S} p \\
\text { value }\end{array}$} & \multirow{2}{*}{$\begin{array}{l}{ }^{\delta} p \\
\text { value }\end{array}$} \\
\hline & & & & & & & & \\
\hline \multirow[t]{6}{*}{ Injury side } & Extensor & Normal BMI group & $0.71 \pm 0.48$ & $1.05 \pm 0.45^{\ddagger}$ & $1.23 \pm 0.56^{\S \delta}$ & 0.025 & 0.017 & 0.050 \\
\hline & & High BMI group & $0.75 \pm 0.37$ & $0.77 \pm 0.40$ & $0.88 \pm 0.40$ & 0.816 & 0.224 & 0.191 \\
\hline & & ${ }^{\dagger} p$ value & 0.903 & 0.105 & 0.105 & & & \\
\hline & Flexor & Normal BMI group & $0.58 \pm 0.30$ & $0.83 \pm 0.18^{\ddagger}$ & $1.06 \pm 0.29^{\S \delta}$ & 0.050 & 0.012 & 0.012 \\
\hline & & High BMl group & $0.68 \pm 0.27$ & $0.70 \pm 0.24$ & $0.84 \pm 0.25^{\S}$ & 0.737 & 0.019 & 0.079 \\
\hline & & ${ }^{\dagger} p$ value & 0.358 & 0.209 & 0.092 & & & \\
\hline \multirow[t]{6}{*}{ Uninjured side } & Extensor & Normal BMI group & $1.24 \pm 0.53$ & $1.61 \pm 0.44$ & $1.58 \pm 0.50^{\S}$ & 0.093 & 0.017 & 0.889 \\
\hline & & High BMl group & $1.18 \pm 0.37$ & $1.38 \pm 0.45$ & $1.52 \pm 0.44^{\S}$ & 0.098 & 0.004 & 0.301 \\
\hline & & ${ }^{\dagger} p$ value & 0.759 & 0.178 & 0.806 & & & \\
\hline & Flexor & Normal BMI group & $0.80 \pm 0.21$ & $1.08 \pm 0.24^{\ddagger}$ & $1.09 \pm 0.25^{\S}$ & 0.028 & 0.012 & 1.000 \\
\hline & & High BMl group & $0.87 \pm 0.25$ & $0.98 \pm 0.27$ & $1.02 \pm 0.31$ & 0.098 & 0.070 & 0.756 \\
\hline & & ${ }^{\dagger} p$ value & 0.426 & 0.462 & 0.602 & & & \\
\hline
\end{tabular}




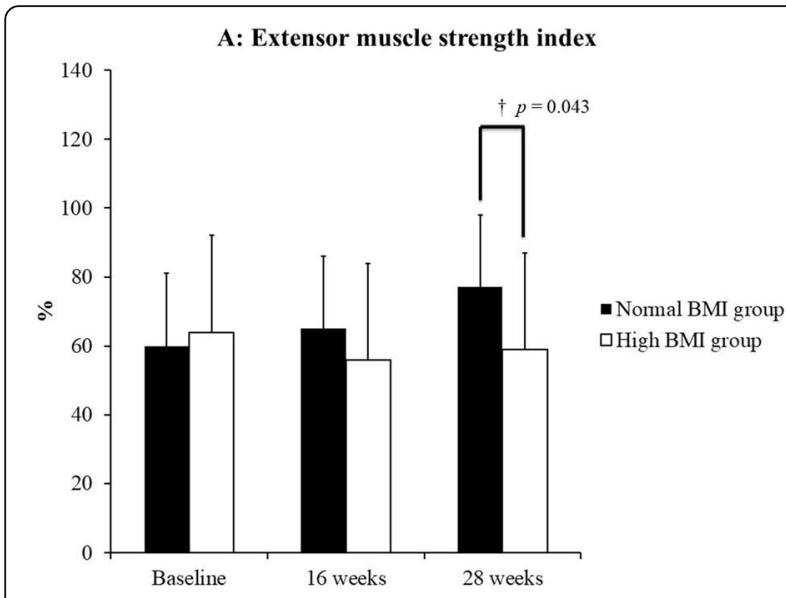

B: Flexor muscle strength index

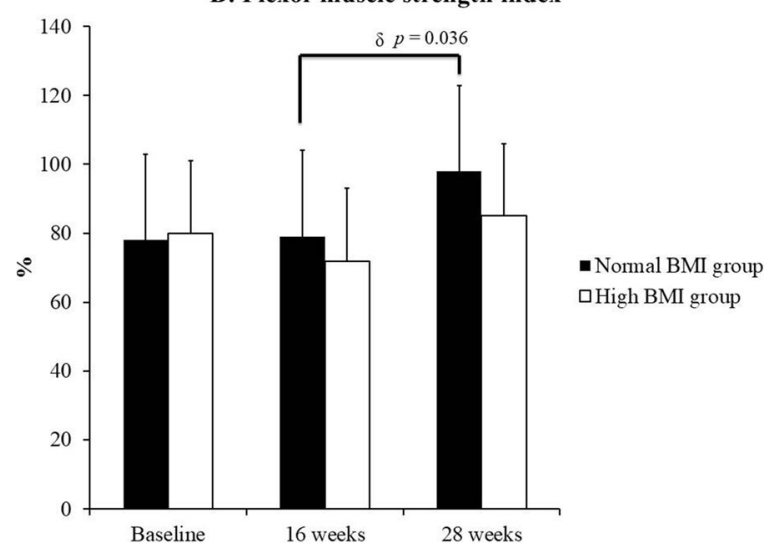

Fig. 1 Knee muscle strength index (Injured side/Uninjured side*100\%); a extensor muscle strength index; $\mathbf{b}$ flexor muscle strength index. $t p$ $<0.05$ between normal and high BMl group; $\delta p<.05$ between

16 weeks and 28 weeks

score increased from $36 \pm 20$ to $52 \pm 22$ at 16 weeks after surgery and further to $64 \pm 17$ at 28 weeks $(p \leq 0.05)$. For the normal BMI group, an increase in the pain subcategory was demonstrated from $75 \pm 15$ at 16 weeks to 84 . \pm 13 at the 28-week follow-up (Table 5).

\section{Discussion}

The present study found that high BMI patients (BMI $\geq$ 25) had improving quadriceps muscle strength in the un-injured knee, while normal BMI patients had improvements in the both injured and uninjured knees. This study parallels the literature, in that normal BMI patients have an extensor symmetry index approaching $80 \%$ at 6 -month follow-up [15, 32, 33]. However, such improvement was not shown in high BMI patients. Second, preoperative quality of life was shown inferior in the high BMI group as compared to the normal BMI group, and improved at 28 weeks after ACL reconstruction. Similarly, the score improved in symptoms, pain, sports, and ADL in the high BMI patients. Interestingly, the normal BMI group had only improvement in the pain subcategory, despite recovery of better muscle strength.

Utilizing strength/body weight ratio, we observed that both the normal and high BMI groups have similar flexor and extensor strength for the uninjured knee at 28 weeks follow-up. It seemed that the strength/ body weight would reach a plateau either in the high or normal BMI patients in the uninjured knee, while a persistent deficit was observed in the injured knee and to a greater extent in the high BMI group. The injured knee showed a pattern where the normal BMI group had progressive increases in both knee flexors and extensors, reaching symmetry indexes of $77 \%$ and $90 \%$, respectively, while the high BMI group had no significant increases in extensor strength. Hence, the symmetry index for the extensor muscle was shown a significant difference between the high and normal BMI groups at the 28 week follow-up.

Literature suggests that the deficit in quadriceps strength for ACL deficient patients is greater than the deficit in hamstring strength [32, 34, 35]. This deficit in strength can be improved by an exercise program after $\mathrm{ACL}$ reconstruction, and recovery of strength in the flexor is faster than in the extensor [36,37]. The present study exhibited similar patterns, and further showed that high BMI patients had a slower recovery of extensor muscle strength. The muscle strength deficit may result from arthrogenic muscle inhibition or quadriceps corticospinal excitability $[13,14]$. It has been suggested that the cortical silent period ( $\mathrm{CSP}$ ) duration is longer in the injured limb of the ACL group, as compared to the uninjured limb [13]. The current study has shown that high BMI was associated with a greater duration of muscle strength deficit. Changed activation of quadriceps and with altered neuromuscular control was shown in obese patients [38]. The quadriceps symmetry index did not reach the desired high quadriceps index $(>90 \%)$ that which is suggested to be biomechanically advantageous after ACL reconstruction $[8,19,21]$. Neuromuscular training incorporating motor learning principles, such as eccentric training which was most effective in restoring quadriceps strength, should be added to strength training to optimize outcome measurements [39].

Increasing BMI was associated with a progressive reduction in physical functions [40, 41]. The deficit extended to those patients suffered from musculoskeletal disorders such as arthropathy and ACL ruptures. Surgical interventions, i.e. total knee arthroplasty (TKA) and ACL reconstructions, would result in comparable functional improvement irrespective of different BMIs [6, 42-44]. Interestingly, effect of BMI on pain for TKA and ACL reconstructed patients was shown a similar 
Table $5 \mathrm{KOOS}$

\begin{tabular}{|c|c|c|c|c|c|c|c|}
\hline & & Baseline & 16 weeks & 28 weeks & ${ }^{\ddagger} p$ value & ${ }^{\S} p$ value & ${ }^{\delta} p$ value \\
\hline & & Mean $\pm S D$ & Mean $\pm S D$ & Mean $\pm S D$ & & & \\
\hline Symptoms & Normal BMl group & $67 \pm 16$ & $68 \pm 19$ & $71 \pm 16$ & 0.889 & 0.483 & 0.528 \\
\hline & High BMl group & $62 \pm 17$ & $65 \pm 18$ & $74 \pm 15 \S \delta$ & 0.594 & 0.023 & 0.023 \\
\hline & ${ }^{\dagger} p$ value & 0.407 & 0.519 & 0.690 & & & \\
\hline Pain & Normal BMI group & $78 \pm 17$ & $75 \pm 15$ & $84 \pm 13 \delta$ & 0.735 & 0.400 & 0.027 \\
\hline & High BMI group & $74 \pm 19$ & $80 \pm 14$ & $87 \pm 10 \S \delta$ & 0.605 & 0.001 & 0.008 \\
\hline & ${ }^{\dagger} p$ value & 0.602 & 0.481 & 0.407 & & & \\
\hline $\mathrm{ADL}$ & Normal BMl group & $83 \pm 19$ & $87 \pm 12$ & $91 \pm 11$ & 0.401 & 0.128 & 0.108 \\
\hline & High BMI group & $78 \pm 20$ & $81 \pm 18$ & $91 \pm 8^{\S \delta}$ & 0.326 & 0.012 & 0.004 \\
\hline & ${ }^{\dagger} p$ value & 0.443 & 0.408 & 0.443 & & & \\
\hline Sports/Rec & Normal BMI group & $50 \pm 30$ & $55 \pm 17$ & $71 \pm 19$ & 0.623 & 0.089 & 0.090 \\
\hline & High BMI group & $36 \pm 20$ & $52 \pm 22+$ & $64 \pm 19^{\S}$ & 0.018 & 0.001 & 0.097 \\
\hline & † $p$ value & 0.207 & 0.517 & 0.422 & & & \\
\hline QOL & Normal BMI group & $53 \pm 16^{\dagger}$ & $58 \pm 18$ & $65 \pm 12$ & 0.344 & 0.131 & 0.235 \\
\hline & High BMI group & $38 \pm 11$ & $52 \pm 19^{\ddagger}$ & $58 \pm 23^{\S}$ & 0.008 & 0.002 & 0.274 \\
\hline & ${ }^{\dagger} p$ value & 0.010 & 0.338 & 0.306 & & & \\
\hline
\end{tabular}

$A D L$ Activities of Daily Living, Sports/Rec function, sports and recreational activities, QOL knee-related Quality of Life ${ }^{\dagger} p \leq 0.05$ between normal and high BMI group

${ }^{\S} p \leq .05$ between baseline and 28 weeks

${ }^{\ddagger} p \leq .05$ between baseline and 16 weeks

${ }^{\delta} p \leq .05$ between 16 weeks and 28 weeks

pattern. In TKA patients, preoperative WOMAC (Western Ontario and McMaster Universities Osteoarthritis Index) pain score was worse as the BMI increased. TKA surgery resulted in a faster improvement in the higher BMI group at 6 month but reached a comparable level across all BMIs at 2 year [45]. In ACL reconstructed patients, faster improvement of pain score was also observed in high BMI patients [6]. In the present study, we demonstrated a significant improvement in KOOS pain subscales in 6 month follow up in the high BMI groups. In addition, we further showed that the high BMI group had improvement in all KOOS subscales, along with an increased muscle strength in the flexor of the injured knee. This could be attributed to, as least in part, the fact that the high BMI group had lower preoperative scores. In the high BMI group, ACL reconstruction providing for re-establishment of static stabilization, along with increased flexor muscle strength, may contribute to the improvement of KOOS. Increased knee muscle strength, mainly in the knee flexors, has been associated with lower activity limitations [46].

The current study was limited by the small number of patients and the relatively short follow-up. Longer-term follow-up is warranted to investigate muscle strength and functional recovery after ACL reconstruction for both normal and high BMI groups. However, this study demonstrated decreased quadriceps muscle strength recovery in the ACL reconstructed knee for higher BMI patients than for normal BMI patients at 6 months follow-up. It is suggested that further rehabilitation should include resistance training and neuromuscular facilitation in high BMI ACL reconstruction patients.

\section{Conclusion}

In the current study, the normal BMI patients had improvement in all knee muscle strength following ACL reconstruction, while high BMI patients only had increases in certain knee muscles. High BMI patients had a decreased quadriceps muscle symmetry index, as compared to their normal BMI counterparts. Increases in quadriceps muscle strength of the uninjured knee and ACL reconstruction were associated with improvements in KOOS in high BMI patients.

\section{Abbreviations}

ACL: Anterior cruciate ligament; ADL: Activities of daily living; BMI: Body mass index; CSP: Cortical silent period; KOOS: Knee injury and Osteoarthritis Outcome Score; QOL: Knee-related quality of life; Sports/Rec: Function, sports and recreational activities; TKA: Total knee arthroplasty; WOMAC: Western Ontario and McMaster Universities Osteoarthritis Index

\section{Funding}

Financial support from Chang Gung Memorial Hospital Grant CORPG6C0033 and CORPG6G0271 are appreciated. There was no external funding.

\section{Availability of data and materials}

The rest of the data are available from the corresponding author upon reasonable request. 


\section{Authors' contributions}

WHH and CHF designed the study and drafted the manuscript. WHH revised it critically. CHF and PAY performed the assessments and statistical analysis. CLC, LTK, and RWWH contributed substantially to the conception and design of the study. All authors have read and approved the final manuscript.

\section{Ethics approval and consent to participate}

This study was approved by the Chang Gung Medical Foundation Institutional Review Board (IRB:102-0977B) that approved consent was written. All patients provided written informed consent

\section{Consent for publication}

Not applicable.

\section{Competing interests}

The authors declare that they have no competing interests.

\section{Publisher's Note}

Springer Nature remains neutral with regard to jurisdictional claims in published maps and institutional affiliations.

\section{Author details}

'Sports Medicine Center, Chang Gung Memorial Hospital at Chia Yi, Chia Yi, Taiwan. ${ }^{2}$ Department of Orthopaedic Surgery, Chang Gung Memorial Hospital at Chia Yi, No 6 West section, Chia Pu Road, Puzih, Chia Yi Hsien 613, Taiwan. ${ }^{3}$ School of Medicine, Chang Gung University, Tao-Yuan, Taiwan.

\section{Received: 29 November 2017 Accepted: 24 September 2018}

\section{Published online: 10 October 2018}

\section{References}

1. Mohtadi N. Development and validation of the quality of life outcome measure (questionnaire) for chronic anterior cruciate ligament deficiency. Am J Sports Med. 1998;26(3):350-9.

2. Lentz TA, Tillman SM, Indelicato PA, Moser MW, George SZ, Chmielewski TL Factors associated with function after anterior cruciate ligament reconstruction. Sports Health. 2009;1(1):47-53.

3. Magnussen RA, Spindler KP. The effect of patient and injury factors on longterm outcome after anterior cruciate ligament reconstruction. Curr Orthop Pract. 2011;22(1):90-103.

4. Kowalchuk DA, Harner CD, Fu FH, Irrgang JJ. Prediction of patient-reported outcome after single-bundle anterior cruciate ligament reconstruction. Arthroscopy. 2009;25(5):457-63.

5. Lebel B, Hulet C, Galaud B, Burdin G, Locker B, Vielpeau C. Arthroscopic reconstruction of the anterior cruciate ligament using bone-patellar tendonbone autograft: a minimum 10-year follow-up. Am J Sports Med. 2008;36(7): 1275-82.

6. Ballal MS, Khan Y, Hastie G, Hatcher A, Coogan S, McNicholas MJ. Functional outcome of primary hamstring anterior cruciate ligament reconstruction in patients with different body mass index classes. Arthroscopy. 2013;29(8): 1314-21.

7. Lynch AD, Logerstedt DS, Axe MJ, Snyder-Mackler L. Quadriceps activation failure after anterior cruciate ligament rupture is not mediated by knee joint effusion. J Orthop Sports Phys Ther. 2012;42(6):502-10.

8. Lewek M, Rudolph K, Axe M, Snyder-Mackler L. The effect of insufficient quadriceps strength on gait after anterior cruciate ligament reconstruction. Clin Biomech. 2002;17(1):56-63.

9. Snyder-Mackler L, De Luca PF, Williams PR, Eastlack ME, Bartolozzi AR, 3rd. Reflex inhibition of the quadriceps femoris muscle after injury or reconstruction of the anterior cruciate ligament. J Bone Joint Surg Am. 1994;76(4):555-60.

10. Hiemstra LA, Webber S, MacDonald PB, Kriellaars DJ. Knee strength deficits after hamstring tendon and patellar tendon anterior cruciate ligament reconstruction. Med Sci Sports Exerc. 2000;32(8):1472-9.

11. Thomas AC, Villwock M, Wojtys EM, Palmieri-Smith RM. Lower extremity muscle strength after anterior cruciate ligament injury and reconstruction. J Athl Train. 2013;48(5):610-20

12. Chmielewski TL, Stackhouse S, Axe MJ, Snyder-Mackler L. A prospective analysis of incidence and severity of quadriceps inhibition in a consecutive sample of 100 patients with complete acute anterior cruciate ligament rupture. J Orthop Res. 2004;22(5):925-30.
13. Ward SH, Pearce A, Bennell KL, Peitrosimone B, Bryant AL. Quadriceps cortical adaptations in individuals with an anterior cruciate ligament injury. Knee. 2016;23(4):582-7

14. Kuenze C, Hertel J, Hart JM. Effects of exercise on lower extremity muscle function after anterior cruciate ligament reconstruction. J Sport Rehabil. 2013;22(1):33-40.

15. de Jong SN, van Caspel DR, van Haeff MJ, Saris DB. Functional assessment and muscle strength before and after reconstruction of chronic anterior cruciate ligament lesions. Arthroscopy. 2007;23(1):21-8 28 e21-23.

16. Eitzen I, Holm I, Risberg MA. Preoperative quadriceps strength is a significant predictor of knee function two years after anterior cruciate ligament reconstruction. Br J Sports Med. 2009;43(5):371-6.

17. Zwolski C, Schmitt LC, Quatman-Yates C, Thomas S, Hewett TE, Paterno MV. The influence of quadriceps strength asymmetry on patient-reported function at time of return to sport after anterior cruciate ligament reconstruction. Am J Sports Med. 2015;43(9):2242-9.

18. Logerstedt D, Lynch A, Axe MJ, Snyder-Mackler L. Pre-operative quadriceps strength predicts IKDC2000 scores 6 months after anterior cruciate ligament reconstruction. Knee. 2013;20(3):208-12.

19. Palmieri-Smith RM, Lepley LK. Quadriceps strength asymmetry after anterior cruciate ligament reconstruction alters knee joint biomechanics and functional performance at time of return to activity. Am J Sports Med. 2015;43(7):1662-69.

20. Pua YH, Seah FJ, Seet FJ, Tan JW, Liaw JS, Chong HC. Sex differences and impact of body mass index on the time course of knee range of motion, knee strength, and gait speed after Total knee arthroplasty. Arthritis Care Res (Hoboken). 2015;67(10):1397-405.

21. Di Stasi SL, Logerstedt D, Gardinier ES, Snyder-Mackler L. Gait patterns differ between $\mathrm{ACL}$-reconstructed athletes who pass return-to-sport criteria and those who fail. Am J Sports Med. 2013;41(6):1310-8.

22. Laboute E, Savalli L, Puig P, Trouve P, Sabot G, Monnier G, Dubroca B. Analysis of return to competition and repeat rupture for 298 anterior cruciate ligament reconstructions with patellar or hamstring tendon autograft in sportspeople. Ann Phys Rehabil Med. 2010;53(10):598-614.

23. Konishi Y, Fukubayashi T. Relationship between muscle volume and muscle torque of the hamstrings after anterior cruciate ligament reconstruction. J Sci Med Sport. 2010;13(1):101-5.

24. Lepley LK, Wojtys EM, Palmieri-Smith RM. Combination of eccentric exercise and neuromuscular electrical stimulation to improve biomechanical limb symmetry after anterior cruciate ligament reconstruction. Clin Biomech (Bristol, Avon). 2015;30(7):738-47.

25. Hsu WH, Hsu RW, Lin ZR, Fan CH. Effects of circuit exercise and tai chi on body composition in middle-aged and older women. Geriatr Gerontol Int. 2015:15(3):282-8.

26. World HO. Obesity: preventing and managing the global epidemic. Report of a WHO consultation. In: WHO technical report series 894. Geneva: WHO; 2000.

27. Roos EM, Roos HP, Lohmander LS, Ekdahl C, Beynnon BD. Knee injury and osteoarthritis outcome score (KOOS)--development of a self-administered outcome measure. J Orthop Sports Phys Ther. 1998:28(2):88-96.

28. Marx RG, Stump TJ, Jones EC, Wickiewicz TL, Warren RF. Development and evaluation of an activity rating scale for disorders of the knee. Am J Sports Med. 2001;29(2):213-8

29. Sekir U, Gur H, Akova B. Early versus late start of isokinetic hamstringstrengthening exercise after anterior cruciate ligament reconstruction with patellar tendon graft. Am J Sports Med. 2010;38(3):492-500.

30. Shaw T, Williams MT, Chipchase LS. Do early quadriceps exercises affect the outcome of ACL reconstruction? A randomised controlled trial. Aust J Physiother. 2005;51(1):9-17.

31. Hooper DM, Morrissey MC, Drechsler W, Morrissey D, King J. Open and closed kinetic chain exercises in the early period after anterior cruciate ligament reconstruction. Improvements in level walking, stair ascent, and stair descent. Am J Sports Med. 2001:29(2):167-74.

32. Lee $\mathrm{DH}$, Lee $\mathrm{JH}$, Jeong $\mathrm{HJ}$, Lee $\mathrm{SJ}$. Serial changes in knee muscle strength after anterior cruciate ligament reconstruction using hamstring tendon autografts. Arthroscopy. 2015;31(5):890-5.

33. Lepley LK. Deficits in quadriceps strength and patient-oriented outcomes at return to activity after $\mathrm{ACL}$ reconstruction: a review of the current literature. Sports Health. 2015;7(3):231-8.

34. Eriksson K, Hamberg P, Jansson E, Larsson H, Shalabi A, Wredmark T. Semitendinosus muscle in anterior cruciate ligament surgery: morphology and function. Arthroscopy. 2001;17(8):808-17. 
35. Kim HJ, Lee JH, Ahn SE, Park MJ, Lee DH. Influence of anterior cruciate ligament tear on thigh muscle strength and hamstring-to-quadriceps ratio: a meta-analysis. PLoS One. 2016;11(1):e0146234.

36. Blanpied P, Carroll R, Douglas T, Lyons M, Macalisang R, Pires L. Effectiveness of lateral slide exercise in an anterior cruciate ligament reconstruction rehabilitation home exercise program. J Orthop Sports Phys Ther. 2000; 30(10):602-8 discussion 609-611.

37. Sasaki S, Tsuda E, Hiraga Y, Yamamoto Y, Maeda S, Sasaki E, Ishibashi Y. Prospective randomized study of objective and subjective clinical results between double-bundle and single-bundle anterior cruciate ligament reconstruction. Am J Sports Med. 2016:44(4):855-64.

38. Amiri P, Hubley-Kozey CL, Landry SC, Stanish WD, Astephen Wilson JL. Obesity is associated with prolonged activity of the quadriceps and gastrocnemii during gait. J Electromyogr Kinesiol. 2015;25(6):951-8.

39. Gokeler A, Bisschop M, Benjaminse A, Myer GD, Eppinga P, Otten E. Quadriceps function following ACL reconstruction and rehabilitation: implications for optimisation of current practices. Knee Surg Sports Traumatol Arthrosc. 2014;22(5):1163-74.

40. Derraik JG, de Bock M, Hofman PL, Cutfield WS. Increasing BMI is associated with a progressive reduction in physical quality of life among overweight middle-aged men. Sci Rep. 2014;4:3677.

41. Giuli C, Papa R, Bevilacqua R, Felici E, Gagliardi C, Marcellini F, Boscaro M, De Robertis M, Mocchegiani E, Faloia E, et al. Correlates of perceived health related quality of life in obese, overweight and normal weight older adults: an observational study. BMC Public Health. 2014;14:35.

42. Stevens-Lapsley JE, Petterson SC, Mizner RL, Snyder-Mackler L. Impact of body mass index on functional performance after total knee arthroplasty. J Arthroplast. 2010;25(7):1104-9.

43. Singh JA, Gabriel SE, Lewallen DG. Higher body mass index is not associated with worse pain outcomes after primary or revision total knee arthroplasty. J Arthroplast. 2011;26(3):366-74 e361.

44. Jarvenpaa J, Kettunen J, Soininvaara T, Miettinen H, Kroger H. Obesity has a negative impact on clinical outcome after total knee arthroplasty. Scand J Surg. 2012;101(3):198-203.

45. Gillespie GN, Porteous AJ. Obesity and knee arthroplasty. Knee. 2007;14(2): 81-6.

46. Sanchez-Ramirez DC, van der Leeden $M$, van der Esch M, Roorda LD, Verschueren S, van Dieen J, Lems WF, Dekker J. Increased knee muscle strength is associated with decreased activity limitations in established knee osteoarthritis: two-year follow-up study in the Amsterdam osteoarthritis cohort. J Rehabil Med. 2015;47(7):647-54.

Ready to submit your research? Choose BMC and benefit from:

- fast, convenient online submission

- thorough peer review by experienced researchers in your field

- rapid publication on acceptance

- support for research data, including large and complex data types

- gold Open Access which fosters wider collaboration and increased citations

- maximum visibility for your research: over $100 \mathrm{M}$ website views per year

At $\mathrm{BMC}$, research is always in progress.

Learn more biomedcentral.com/submissions 